samples include patients on maintenance oral corticosteroids. In patients with difficult asthma, multiple or atypical symptoms, there should be a low threshold to investigate for adrenal insufficiency particularly those receiving high dose ICS.

\section{P10 RANDOMISED PLACEBO CONTROLLED TRIAL TO EVALUATE CHRONIC DOSING EFFECTS OF PROPRANOLOL IN STEROID TREATED PERSISTENT ASTHMATICS}

doi:10.1136/thoraxjnl-2012-202678.151

PM Short, PA Williamson, WJ Anderson, BJ Lipworth. Asthma and Allergy Research Group, Medical Research Institute, University of Dundee, Dundee, United Kingdom

Introduction and Objectives Beta-blockers are associated with acute bronchospasm in asthmatics. However preliminary unblinded studies have shown potential therapeutic benefits with chronic beta-blockade on airway hyper-responsiveness (AHR) in steroid naïveasthmatics. We examined the effects on AHR of propranolol versus placebo in steroid treated persistent asthmatics.

Methods A double-blind randomised placebo controlled crossover trial of propranolol in mild-to-moderate asthmatics receiving inhaled corticosteroids (ICS) was performed (NCT01074853). Participants underwent a six to eight week dose titration of propranolol or placebo as tolerated to a maximum of $80 \mathrm{mg}$ per day. Tiotropium was given concurrently for the first four to six weeks of each treatment period. Primary outcome was methacholine challenge (without tiotropium). Secondary outcomes included histamine challenge (with and without tiotropium), pulmonary function, heart rate, blood pressure, mini-asthma quality of life questionnaire (miniAOLQ) and asthma control questionnaire (ACQ).

Results 18 patients completed: mean (SEM); age 36 (4), FEV $_{1} \% 93$ (2), ICS ug/day 440 (66). No significant difference was observed in methacholine or histamine challenge following exposure to propranolol versus placebo. For methacholine challenge (without tiotropium) the doubling dilution difference (DDD) was 0.04 (95\%CI $-0.56-0.63), p=0.89$. For histamine challenge without tiotropium the DDD was $0.42(95 \% \mathrm{CI}-0.09-0.93), \mathrm{p}=0.10$; and with tiotropium was DDD $0.26(95 \% \mathrm{CI}-0.36-0.87), p=0.39$. Salbutamol induced chronotropic response was significantly blunted following propranolol versus placebo: mean difference $25 \mathrm{bpm}$ (95\%CI $14-37), p<0 \cdot 001$. No difference was found for ACQ, mean difference 0.18 ( $95 \% \mathrm{CI}-0 \cdot 23-0.58), p=0.79$ or mini-AOLQ, mean difference $0.14(95 \% \mathrm{CI}-0 \cdot 19-0 \cdot 46), p=0 \cdot 84$

Conclusions This is the first placebo controlled study to assess the effects of chronic non selective beta-blockade in steroid treated persistent asthmatics, showing no significant effect of propranolol compared to placebo on AHR to either methacholine or histamine and no change in ACQ or AOLO.

\section{P11 REDUCTION IN HEALTHCARE RESOURCE UTILISATION WITH 2 YEARS TREATMENT WITH OMALIZUMAB IN SEVERE ATOPIC ASTHMATICS: A SINGLE CENTRE OBSERVATION}

doi:10.1136/thoraxjnl-2012-202678.152

H Cummings, J Thompson, A Bell, J Morjaria. Hull and East Yorkshire Hospitals, HUII, England

Background While asthma is a chronic inflammatory disorder that is managed with inhaled controller and reliever drugs, there remains a large unmet need at the severe end of the disease spectrum.

Omalizumab is licenced as add-on therapy for patients with uncontrolled severe persistent atopic (IgE-mediated) asthma.

Aim Retrospective review of healthcare utilisation and clinical outcomes of the efficacy of Omalizumab administered as per NICE approval on a 2- or 4-weekly basis in adults with severe allergic asthma in our tertiary centre in Hull.
Methods We compared data in our cohort of patients on Omalizumab therapy at 2-years pre-Omalizumab, 16-weeks, 1- and 2 -years post-Omalizumab. Our primary outcome was healthcare utilisation (asthma-related hospital admissions, bed and critical care bed days, oral corticosteroid courses (OCS) and reduction in overall OCS dose). Secondary parameters assessed included subjective (asthma control test (ACT), and quality-of-life (AOLO) and its domain scores) and objective parameters (spirometry and morning peak flows) outcomes.

Results Our 9 patients ( 2 M, 7 F) on Omalizumab therapy had an average $( \pm S D)$ age of $52( \pm 11.9)$ Overall in-hospital admissions reduced from 28 days in the 2 years pre-Omalizumab to 0,4 and 3 days at 16-weeks, 1 - and 2-years respectively. Correspondingly, medical bed days diminished from 163 pre-treatment to 0,17 and 10 at 16-weeks, 1- and 2-years respectively. Astonishingly, critical care bed day's utility declined from 36 pre-Omalizumab, to 0 at all postOmalizumab time points. Furthermore, total OCS courses usage reduced noticeably from 39 pre-treatment to 5,9 and 10 at 16-weeks, 1 - and 2-years respectively. There were marked improvements in AOLO and its domains, and ACT scores, however changes in objective measures assessed were minimal (see Table 1)

Conclusion Results from our single centre, in a small cohort of severe atopic asthmatics treated with Omalizumab, have shown striking reductions in healthcare resource utilisation, OCS use and subjective assessments compared to the two years prior to its initiation. This real-life effectiveness of Omalizumab supports its utility in this group of severely allergic asthmatics refractory to standard treatment.

\section{P12 FLUTICASONE PROPIONATE/FORMOTEROL FUMARATE COMBINATION THERAPY: TREATMENT EFFECTS IN PATIENTS BY BASELINE ASTHMA SEVERITY ACROSS THE DOSE RANGE}

doi:10.1136/thoraxjnl-2012-202678.153

T Mclver, B Grothe, M Jain, S Dissanayake. Mundipharma Research Limited, Cambridge, United Kingdom

Background A new asthma therapy containing a combination of the inhaled steroid fluticasone propionate (FLUT) and the longacting $\beta_{2}$ agonist (LABA) formoterol fumarate (FORM) in a metereddose inhaler has been developed (FLUT/FORM; flutiform ${ }^{\circledR}$ ). In a double-blind, double-dummy, randomised, multicentre, four arm parallel group study, the efficacy and safety of FLUT/FORM vs. FLUT and FORM administered concurrently (FLUT+FORM) was assessed. Here, we present efficacy results of a post-hoc analysis that compared FLUT/FORM 500/20 $\mu \mathrm{g}$ with FLUT/FORM 100/10 $\mu \mathrm{g}$ (both twice-daily) by baseline asthma severity.

Methods In total, 620 patients were randomised 1:1:1:1 to receive FLUT/FORM 500/20 $\mu \mathrm{g}$, FLUT/FORM 100/10 $\mu \mathrm{g}$, FLUT+FORM $500 \mu \mathrm{g}+24 \mu \mathrm{g}$ or FLUT $500 \mu \mathrm{g}$. Randomisation was stratified by percentage predicted $\mathrm{FEV}_{1}$ at baseline [ $\geq 40-\leq 60 \%$ ('severe asthma'; $52 \%$ of patients) vs. $>60 \%-\leq 80 \%$ ('moderate asthma'; $48 \%$ of patients)], allowing a post-hoc dichotomised analysis by baseline FEV , severity of spirometric and symptom-based endpoints.

Results There was no dose-response relationship between FLUT/ FORM 500/20 $\mu \mathrm{g}$ and FLUT/FORM 100/10 $\mu \mathrm{g}$ for the spirometric variables overall or in either subgroup.

Treatment effect differences between FLUT/FORM 500/20 $\mu \mathrm{g}$ and $100 / 10 \mu \mathrm{g}$, in favour of the high dose, were however evident for almost all symptom-based endpoints and were more pronounced in the severe asthma group. These included changes in: mean symptom scores, percentage symptom-free days, mean sleep disturbance scores, awakening free nights, percentage rescue medication-free days, percentage asthma control days, AOLO score and the incidence of any asthma exacerbations. The differences between FLUT/ 